\title{
Multi-Criteria and Multi-Stage Facility Location Selection under Interval Type-2 Fuzzy Environment: A Case Study for a Cement Factory
}

\author{
Ferhan Çebi ${ }^{*}$, İrem Otay \\ Dept of Management Engineering, Faculty of Management, \\ Istanbul Technical University, \\ Macka 34367, Istanbul, Turkey \\ E-mail: cebife@itu.edu.tr,iremotay@itu.edu.tr \\ www.itu.edu.tr
}

Received 22 October 2013

Accepted 10 November 2014

\begin{abstract}
The study proposes a comprehensive and systematic approach for multi-criteria and multi-stage facility location selection problem. To handle with high and more uncertainty in the evaluation and selection processes, the problem is solved by using multi-criteria decision making technique with interval Type- 2 fuzzy sets. The study contributes the facility location selection literature by introducing the application of fuzzy TOPSIS method with interval Type2 fuzzy sets. Finally, the suggested approach is applied to a real life region and site selection problem of a cement factory.

Keywords: Type-2 fuzzy sets, Facility location selection, Fuzzy TOPSIS, multi-criteria, decision making.
\end{abstract}

*Corresponding author: cebife@itu.edu.tr, Tel: +(90) 2122931300 Ext:2034 


\section{Introduction}

Facility location selection is one of the subjects drawing utmost attention from both academicians and practitioners for over several decades because of its critical and strategic importance on organizations' performance, profitability, competitiveness, and survival. The literature has highlighted the necessity of a systematic approach to the process of evaluation and selection of a geographic area on which organizations will locate a new facility. The process requires consideration of several factors from social to economic factors, from qualitative to quantitative factors, and from strategic to operational factors. ${ }^{1-2-3-4}$ Therefore, as a complex topic, facility location selection is a typical multi-criteria decision making (MCDM) problem requiring macro and micro analysis for assessing the alternatives.

The literature shows that location factors and their impact levels on decision making processes mostly vary regarding to the types of facilities, and even to the expectations of companies. On the other hand, with globalization, the location selection problem almost all kind of organizations have faced, is a typical multi-stage decision making problem ranging from country selection to site selection, in which factors affecting the location decisions differ. ${ }^{1-2-3}$ In the literature, there are a lot of studies highlighted a multi-stage aspect of a location selection problem. The studies ${ }^{5-6}$ have clearly indicated that the evaluation criteria and the relative importance attributed to the criteria have differed with respect to the decision stages in the evaluation processes. With this regard, this study focuses on multicriteria and multi-stage site selection problem with a variety of criteria to be considered.

In the literature, multi-criteria problem has been criticized with respect to uncertainties and ambiguity in the human judgments and evaluations. So, the fuzziness gets importance for the location selection as a multicriteria problem. Because of decision making problems requiring human judgments and evaluations, the fuzzy methodology is one of the most commonly used approaches that resolve the ambiguity and subjectivity in the evaluations and perceptions of humans. On the other hand, a recent study $^{7}$ has indicated the lack of studies dealing with uncertainty in the evaluation process taking multi-criteria into account.
This study focuses on analyzing location selection problem under fuzzy environment. Different from the location selection literature, the study employed multicriteria decision making technique with Type-2 fuzzy sets during the analysis to handle the uncertainties. The literature has suggested Type-2 fuzzy sets in the case of availability of more and high uncertainty. ${ }^{8}$ Although this kind of problem has inherently more uncertainty, to the best of the authors' knowledge, there is no study applying Type-2 fuzzy sets (T2FSs) for a facility location selection problem. On the other hand, researchers $^{9}$ have highlighted that there have been a limited number of studies involving industrial applications of T2FSs and there has been a need to resolve the problems that were solved by using Type-1 fuzzy sets. So, the motivation for conducting the study comes from the literature review indicating the availability and criticality high uncertainties on the location selection decision making process as well as the lack of studies using Type-2 fuzzy sets to handle uncertainties and vagueness for solving the problems in the multiple industrial environments. The study also contributes to the literature by representing a real industrial problem to show how the organizations can deal with uncertainties and complexities on the decision making processes to select the most appropriate facility locations.

Briefly, the paper aims to solve multi-stage location selection problem by applying fuzzy multi-criteria decision making approach by using Type-2 fuzzy sets. In this pursuit, fuzzy TOPSIS (Technique for Order Preference by Similarity to Ideal Solution) approach with Type-2 fuzzy sets, developed by Chen and Lee ${ }^{10}$ is employed for a location selection problem. Based on a case study, the methodology is considered to help managers make efficient and effective decisions in evaluating and selecting the most appropriate region and site. The remaining of the paper is organized as follows: In Section 2, a comprehensive literature review is stated. In Section 3, the fuzzy method employed in the study is introduced. In Section 4, location selection problem of a cement factory is introduced and analyzed into two stages in which selection of the best appropriate region and selection of the best appropriate site obtaining by using fuzzy multi-criteria decision making approach. In Section 5, the results of the proposed approach are compared with several approaches. In the last section, 
conclusion remarks and suggestions for future studies are presented.

\section{Literature Review}

Lots of studies in the location selection literature were reviewed for conducting this study and developing the evaluation and selection model.

Some studies in the literature have introduced various criteria including economical, social and environmental factors as well as various objectives. Current et al. ${ }^{11}$, for instance, addressed the multiobjective aspect of a location selection problem by dividing the objectives into the groups such as distance minimization, demand, profit maximization and environmental factors. Although site selection in the manufacturing sector has usually been based on cost factor, in recent years environmental and social factors have been growing importance on location selection decisions for plants as indicated by several authors. ${ }^{3-12}$ A study conducted in the cement sector by the authors of Dey and Ramcharan ${ }^{12}$ presented technical factors including resource availability, physical characteristics, economic factors; environmental factors consisting of marine-terrestrial flora and fauna; socio-cultural factors including infrastructure, affects on heritage, proximity of existing operations and national planning factors mainly national and economic policy and physical development for site selection by emphasizing the importance of the site selection for supporting cement production. Tabari et al. ${ }^{13}$ considered tangible factors mainly cost components including land cost, transportation cost, energy cost, raw material cost and critical factors including political factors and marginal risks. Dogan ${ }^{14}$ also introduced tangible attributes such as availability of workforce, population, unemployment rate, education and health system, financial risk level as well as intangible factors such as labor skill, workforce motivation, technological capability, standard of living, and current stability.

The location selection literature has introduced some of the conventional approaches providing systematic steps for solving the problem such as manager's judgments, the check list method, analog approach, regression models, and location allocation models. ${ }^{15-16}$ The authors have highlighted that these approaches have not considered the relationship among the decision factors globally, and the decision from these approaches may reflect the ability and experience of the analysts.

Some authors have employed multi-criteria decision making approaches. For instance, Korpela and Tuominen ${ }^{17}$ considered both qualitative and quantitative criteria and used analytic hierarchy process (AHP) for a warehouse site section problem. Thomas et al. ${ }^{18}$ developed a systematic approach using data envelopment analysis (DEA) and iterative algorithm for obnoxious facility location decision. Partovi ${ }^{19}$ presented quality function deployment (QFD), analytic hierarchy process (AHP) and analytic network process (ANP) approaches to a facility location problem. Dey and Ramcharan ${ }^{12}$ clarified technical, socio-economic and environmental factors and then conducted AHP method to select a site for the quarry expansion project in the Caribbean. Tuzkaya et al. ${ }^{20}$ also used ANP for a facility location selection problem.

Some researchers also employed mathematical models for solving the problem. In the earlier studies, warehousing models, network models, and mixedinteger programming models were presented. ${ }^{21-22-23}$ In one of the studies, dynamic facility location problem was formulated by taking into account uncertainty in the number of facilities. ${ }^{24}$ Badri $^{25}$ integrated AHP and goal programming for a location selection problem. Canel et al. $^{26}$ considered the capacitated, multi-commodity, multi-period and multi-stage facility location problem. Melkote and Daskin ${ }^{27}$ used mixed integer programming for the classical capacitated facility location problem. $\operatorname{Verter}^{28}$ presented an analytical approach for simultaneous optimization of the facility location, capacity acquisition and technology selection decisions. Some studies formulated mathematical models for deterministic and dynamic problems. ${ }^{29-30}$ Klose and Drexl $^{31}$ presented continuous location models, network location models, mixed-integer programming models for a variety of situations such as uncapacitated and capacitated single-stage, multi-stage, as well as dynamic, probabilistic and multi-objective location models. Arabani and Farahani ${ }^{32}$ analyzed single-facility, multi-facility location problems, discrete, network problems and dynamic facility location problems.

On the other hand, to bring solutions to the vagueness and ambiguity in the human judgments, Zadeh $^{33}$ introduced fuzzy set theory in order to express linguistic expressions in the decision making processes. Since the facility location has ambiguity and vagueness 
in its nature, it has also been studying under the fuzzy environment. Therefore, many authors applied fuzzy methodologies and developed fuzzy models to find solutions for facility location selection problems. The researchers introduced various fuzzy multi-criteria facility location evaluation and selection models. For instance, Kahraman et al. ${ }^{34}$ made a comparative analysis of four different approaches which are Blin's approach, the fuzzy synthetic evaluation method, Yager's weighted goals method and lastly fuzzy analytic hierarchy process for the fuzzy multi-attribute facility location problem. Chou et al. ${ }^{35}$ presented a new fuzzy multi-attribute decision making (FMADM) approach namely a fuzzy simple additive weighting system taking into account objective/subjective attributes under group decision making. Shen and $\mathrm{Yu}^{36}$ studied a generalized fuzzy approach for determining the best facility location which was a strategic problem for a company. Some authors used fuzzy TOPSIS approach for site selection decision problems. ${ }^{37-38-39}$ Furthermore, Ngan ${ }^{40}$ presented the extended fuzzy linguistic computing methodology by applying it for the evaluation of the investment benefit of a proposed facility site as well as for a new product idea of an electronics manufacturing firm. Mokhtarian $^{41}$ evaluated gas oil station alternatives by using fuzzy L-R scores.

Literature review has also showed that there is a linguistic uncertainty meaning that same word can mean different for different people. ${ }^{42-43}$ Therefore, increasing fuzziness in other words using higher types (e.g. Type2) helps to cope with inexact information. ${ }^{42}$ Additionally, according to Dereli et al. ${ }^{9}$, when there is high uncertainty, Type-2 fuzzy sets provide reliable and robust results and it is a useful tool to model vagueness and ambiguity. Moreover, some authors ${ }^{44-45}$ have addressed that Type-2 fuzzy sets (T2FSs) may give us more degrees of freedom; so that, T2FSs express uncertainty and vagueness of the real world better. Some others also stated that T2FSs give more flexibility for representing uncertainties than that is for Type-1 fuzzy sets. $^{44}$

There are two types of T2FSs which are interval T2FSs and full T2FSs. Nevertheless, the researchers generally prefer applying interval-valued T2FSs as fulltype version is computationally complex in the case of a lot of number of variables. ${ }^{46-47-48}$ Therefore, in this study interval Type-2 fuzzy sets (IT2FSs) are employed for a real life multi-criteria decision making problem.
The literature provides different types of studies on fuzzy approaches and Type-2 Fuzzy Sets (T2FSs) such as introduction and overview on T2FSs and systems ${ }^{49}$, assessments of various approaches and the applications $^{50}$, literature reviews on the industrial applications 9 . The literature also presents many studies in which Type-2 fuzzy sets were utilized for solving multi-criteria decision making problems, as well as comparative studies. For instance, Sepulveda et al. ${ }^{45}$ made a study comparing Type- 1 and Type- 2 fuzzy sets for the design of control systems and indicated that the best results were obtained from Type-2 fuzzy sets for their problem. Miller and John ${ }^{51}$ used fuzzy IT2FSs for a multi-echelon supply chain problem and they suggested a model which was optimized by one of the heuristic methods, Genetic Algorithm. Kahraman et al. ${ }^{52}$ extended Buckley's fuzzy AHP method by using IT2FSs. Chen ${ }^{53}$ utilized interval Type-2 (IT2) fuzzy linear assignment method with signed distances for the case of landfill site selection. Celik et al. ${ }^{54}$ used IT2FSs for an MCDM problem related with public transportation. Dereli and Altun ${ }^{55}$ employed IT2FSs for a technology evaluation problem. $\mathrm{Ngan}^{56}$ extended the probabilistic linguistic framework to Type-2 linguistic sets for ERP system selection for an electronic toy manufacturing firm. Zhang and Zhang ${ }^{44}$ used integrated interval Type-2 fuzzy set theory and soft set theory for a multi-attribute group decision making problem and presented a numerical example related with a house purchase problem. Zamri and Abdullah ${ }^{57}$ proposed a new linguistic variable considering both positive and negative fuzzy numbers using interval Type-2 entropy weight and fuzzy TOPSIS. Chen and Wang ${ }^{58}$ presented a new fuzzy multiple attribute decision making (MADM) method considering attitude of decision makers towards risks by employing interval Type-2 fuzzy sets. Jiang and Tang ${ }^{59}$ established a fuzzy model for computing with words by using interval Type-2 fuzzy sets. Kahraman et al. ${ }^{60}$ developed an interval Type-2 fuzzy AHP method with a new ranking method. Abdullah and Najib ${ }^{61}$ suggested a new fuzzy AHP with interval Type-2 fuzzy sets. Maali and Mahdavi-Amiri ${ }^{62}$ constructed multi-objective linear programming model with Type-2 fuzzy objectives and developed two solution strategies. The authors also utilized Type- 2 fuzzy sets to rank alternatives in the multi attribute decision making models. ${ }^{63-64-65-66-67-68}$ 
Although in the literature, as indicated above, there were studies using IT2FSs for multi-criteria decision making problems in a variety of application areas, to the authors' best knowledge, there is no study in which IT2FSs are used for a location selection problem. So, the study contributes to the literature by filling this gap in the location selection literature as well as by indicating suitability and applicability of the proposed method to a real life location selection problem.

\section{The Methodology}

This section briefly summarizes the methodology to be utilized in the study for solving the multi-criteria facility location selection problem. Once basic knowledge in Type-2 fuzzy sets and arithmetic operations of Type-2 fuzzy sets are presented, the methodology and the steps of fuzzy TOPSIS approach using Interval Type-2 fuzzy sets are explained.

\subsection{Type-2 Fuzzy Sets}

The concept of Type-2 fuzzy sets was introduced by Zadeh $^{69}$ and it is basically an extension of the concept of Type-1 fuzzy set. ${ }^{44}$ Even though it was introduced in 1970s, there were a few studies related with T2FSs until 1990s. ${ }^{9}$

Researchers applied T2FSs for a variety of reasons. For instance, if precise membership functions are impossible to define and to handle a variety of uncertainties such as linguistic uncertainty, vagueness, incomplete information, Type-2 fuzzy sets are suggested to be used; so that uncertainty can be modeled in a better way. ${ }^{70}$

The membership functions in Type-2 fuzzy sets are expressed with more parameters compared to Type-1 fuzzy sets. ${ }^{9}$ Type-1 fuzzy sets have crisp membership functions in $[0,1]$ whereas Type-2 fuzzy sets have fuzzy membership functions which are expressed with Type-1 fuzzy sets.

In this study, trapezoidal interval Type-2 fuzzy sets are employed. A general representation of Type-2 fuzzy set in the universe of discourse $X$ can be expressed as follows: ${ }^{10}$

$$
\begin{aligned}
& \tilde{\tilde{A}}=\left\{\left((x, u), \mu_{\tilde{\tilde{A}}}\right) \mid \forall x \in X, \forall u \in J_{x} \subseteq[0,1]\right\} \text { where } \\
& 0 \leq \mu_{\tilde{\tilde{A}}}(x, u) \leq 1
\end{aligned}
$$

Other representation of Type-2 fuzzy set is as follows:
$\tilde{\tilde{A}}=\int_{x \in X} \int_{u \in J_{x}} \mu \tilde{\tilde{A}}(x, u) /(x, u)$ where $J_{x} \in[0,1]$

In this formulation $\iint$ implicates the unification of acceptable $x$ and $u$. For both of the equations, when $\mu(\tilde{\tilde{A}})=1, \quad \tilde{\tilde{A}} \quad$ became interval Type-2 fuzzy set. Therefore, it can be said that interval Type-2 fuzzy set is a special version of Type-1 fuzzy set and can be expressed as:

$$
\tilde{\tilde{A}}=\int_{x \in X} \int_{u \in J_{x}} 1 /(x, u) \text { where } J_{x} \in[0,1]
$$

The membership function of an interval Type-2 fuzzy set of $\tilde{\tilde{A}}$ including upper and lower membership functions are constructed by using Type-1 fuzzy membership functions.

$$
\begin{aligned}
& \tilde{\tilde{A}}_{i}=\left(\tilde{A}_{i}^{U}, \tilde{A}_{i}^{L}\right) \\
& \tilde{A}_{i}^{U}=\left(a_{i 1}^{U}, a_{i 2}^{U}, a_{i 3}^{U}, a_{i 4}^{U} ; H_{1}\left(\tilde{A}_{i}^{U}\right), H_{2}\left(\tilde{A}_{i}^{U}\right)\right) \\
& \tilde{A}_{i}^{L}=\left(a_{i 1}^{L}, a_{i 2}^{L}, a_{i 3}^{L}, a_{i 4}^{L} ; H_{1}\left(\tilde{A}_{i}^{L}\right), H_{2}\left(\tilde{A}_{i}^{L}\right)\right) \\
& H_{1}\left(\tilde{A}_{i}^{U}\right), H_{2}\left(\tilde{A}_{i}^{U}\right), H_{1}\left(\tilde{A}_{i}^{L}\right), H_{2}\left(\tilde{A}_{i}^{L}\right) \in[0,1]
\end{aligned}
$$

where $(1 \leq i \leq n)$.

$$
\tilde{A}_{i}^{U} \text { and } \tilde{A}_{i}^{L} \text { are constructed as Type-1 fuzzy sets and }
$$
the reference points of Type-2 fuzzy numbers are denoted as $\underset{a_{i 1}}{U}, a_{i 2}^{U}, a_{i 3}^{U}, a_{i 4}, a_{i 1}, a_{i 2}, a_{i 3}^{L}$ and $a_{i 4} L$.

In the upper and lower trapezoidal membership functions of $\tilde{A}_{i}^{U}$ and $\tilde{A}_{i}^{L}, H_{j}\left(\tilde{A}_{i}^{U}\right)$ and $H_{j}\left(\tilde{A}_{i}^{L}\right)$ implicate the membership values of $a_{i(j+1)}^{U}$ and $a_{i(j+1)}^{L}$ $(1 \leq j \leq 2)$, respectively.

Membership function of interval Type-2 fuzzy set of $\tilde{\tilde{A}}$ is demonstrated in Fig. 1 .

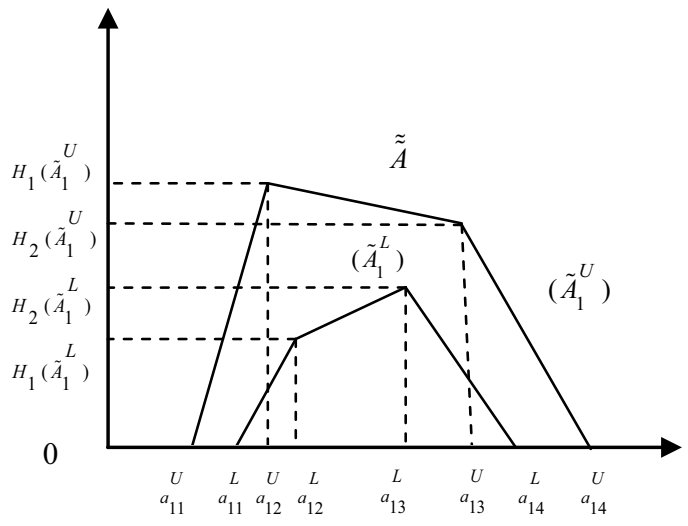

Fig.1. Membership functions of IT2FSs of $\tilde{\tilde{A}}$ 


\subsection{Operations of Type-2 Fuzzy Sets}

There is short information about addition, subtraction, multiplication and arithmetic operations of Type-2 fuzzy sets. ${ }^{10}$

$$
\begin{aligned}
& \tilde{\tilde{A}}_{1}=\left(\tilde{A}_{1}^{U}, \tilde{A}_{1}^{L}\right) \text { and } \tilde{\tilde{A}}_{2}=\left(\tilde{A}_{2}^{U}, \tilde{A}_{2}^{L}\right) ; \\
& \tilde{A}_{1}^{U}=\left(\left(a_{11}^{U}, a_{12}^{U}, a_{13}^{U}, a_{14}^{U} ; H_{1}\left(\tilde{A}_{1}^{U}\right), H_{2}\left(\tilde{A}_{1}^{U}\right)\right) ;\right. \\
& \tilde{A}_{1}^{L}=\left(\left(a_{11}^{L}, a_{12}^{L}, a_{13}^{L}, a_{14}^{L} ; H_{1}\left(\tilde{A}_{1}^{L}\right), H_{2}\left(\tilde{A}_{1}^{L}\right)\right) ;\right. \\
& \tilde{A}_{2}^{U}=\left(\left(a_{21}^{U}, a_{22}^{U}, a_{23}^{U}, a_{24}^{U} ; H_{1}\left(\tilde{A}_{2}^{U}\right), H_{2}\left(\tilde{A}_{2}^{U}\right)\right) ;\right. \\
& \tilde{A}_{2}^{L}=\left(\left(a_{21}^{L}, a_{22}^{L}, a_{23}^{L}, a_{24}^{L} ; H_{1}\left(\tilde{A}_{2}^{L}\right), H_{2}\left(\tilde{A}_{2}^{L}\right)\right) .\right.
\end{aligned}
$$

\section{Addition:}

$$
\begin{aligned}
\tilde{\tilde{A}}_{1} \oplus \tilde{\tilde{A}}_{2}= & \left(\left(a_{11}^{U}+a_{21}^{U}, a_{12}^{U}+a_{22}^{U}, a_{13}^{U}+a_{23}^{U}, a_{14}^{U}+a_{24}^{U} ;\right.\right. \\
& \left.m \operatorname{in}\left(H_{1}\left(\tilde{A}_{1}^{U}\right), H_{1}\left(\tilde{A}_{2}^{U}\right)\right), \min \left(H_{2}\left(\tilde{A}_{1}^{U}\right), H_{2}\left(\tilde{A}_{2}^{U}\right)\right)\right), \\
& \left(a_{11}^{L}+a_{21}^{L}, a_{12}^{L}+a_{22}^{L}, a_{13}^{L}+a_{23}^{L}, a_{14}^{L}+a_{24}^{L} ;\right. \\
& \left.\left.m i \mathrm{n}\left(H_{1}\left(\tilde{A}_{1}^{L}\right), H_{1}\left(\tilde{A}_{2}^{L}\right)\right), \min \left(H_{2}\left(\tilde{A}_{1}^{L}\right), H_{2}\left(\tilde{A}_{2}^{L}\right)\right)\right)\right) .
\end{aligned}
$$

\section{Subtraction:}

$$
\begin{aligned}
\tilde{\tilde{A}}_{1} \Theta \tilde{\tilde{A}}_{2}= & \left(\left(a_{11}^{U}-a_{24}^{U}, a_{12}^{U}-a_{23}^{U}, a_{13}^{U}-a_{22}^{U}, a_{14}^{U}-a_{21}^{U} ;\right.\right. \\
& \left.m \operatorname{in}\left(H_{1}\left(\tilde{A}_{1}^{U}\right), H_{1}\left(\tilde{A}_{2}^{U}\right)\right), \min \left(H_{2}\left(\tilde{A}_{1}^{U}\right), H_{2}\left(\tilde{A}_{2}^{U}\right)\right)\right), \\
& \left(a_{11}^{L}-a_{24}^{L}, a_{12}^{L}-a_{23}^{L}, a_{13}^{L}-a_{22}^{L}, a_{14}^{L}-a_{21}^{L} ;\right. \\
& \left.\left.m \operatorname{in}\left(H_{1}\left(\tilde{A}_{1}^{L}\right), H_{1}\left(\tilde{A}_{2}^{L}\right)\right), \min \left(H_{2}\left(\tilde{A}_{1}^{L}\right), H_{2}\left(\tilde{A}_{2}^{L}\right)\right)\right)\right) .
\end{aligned}
$$

\section{Multiplication:}

$$
\begin{aligned}
\tilde{\tilde{A}}_{1} \otimes \tilde{\tilde{A}}_{2}= & \left(\left(a_{11}^{U} \times a_{21}^{U}, a_{12}^{U} \times a_{22}^{U}, a_{13}^{U} \times a_{23}^{U}, a_{14}^{U} \times a_{24}^{U} ;\right.\right. \\
& \left.m \operatorname{in}\left(H_{1}\left(\tilde{A}_{1}^{U}\right), H_{1}\left(\tilde{A}_{2}^{U}\right)\right), \min \left(H_{2}\left(\tilde{A}_{1}^{U}\right), H_{2}\left(\tilde{A}_{2}^{U}\right)\right)\right), \\
& \left(a_{11}^{L} \times a_{21}^{L}, a_{12}^{L} \times a_{22}^{L}, a_{13}^{L} \times a_{23}^{L}, a_{14}^{L} \times a_{24}^{L} ;\right. \\
& \left.\left.m \operatorname{in}\left(H_{1}\left(\tilde{A}_{1}^{L}\right), H_{1}\left(\tilde{A}_{2}^{L}\right)\right), \min \left(H_{2}\left(\tilde{A}_{1}^{L}\right), H_{2}\left(\tilde{A}_{2}^{L}\right)\right)\right)\right) .
\end{aligned}
$$

\section{Other Arithmetic Operations:}

$$
\begin{aligned}
k \tilde{\tilde{A}}_{1}= & \left(\left(k \times a_{11}^{U}, k \times a_{12}^{U}, k \times a_{13}^{U}, k \times a_{14}^{U} ; H_{1}\left(\tilde{A}_{1}^{U}\right), H_{2}\left(\tilde{A}_{1}^{U}\right)\right),\right. \\
& \left(\left(k \times a_{11}^{L}, k \times a_{12}^{L}, k \times a_{13}^{L}, k \times a_{14}^{L} ; H_{1}\left(\tilde{A}_{1}^{L}\right), H_{2}\left(\tilde{A}_{1}^{L}\right)\right) .\right. \\
\frac{\tilde{A}_{1}}{k}= & \left(\left(\frac{1}{k} \times a_{11}^{U}, \frac{1}{k} \times a_{12}^{U}, \frac{1}{k} \times a_{13}^{U}, \frac{1}{k} \times a_{14}^{U} ; H_{1}\left(\tilde{A}_{1}^{U}\right), H_{2}\left(\tilde{A}_{1}^{U}\right)\right),\right. \\
& \left(\left(\frac{1}{k} \times a_{11}^{L}, \frac{1}{k} \times a_{12}^{L}, \frac{1}{k} \times a_{13}^{L}, \frac{1}{k} \times a_{14}^{L} ; H_{1}\left(\tilde{A}_{1}^{L}\right), H_{2}\left(\tilde{A}_{1}^{L}\right)\right) .\right. \\
(k>0) . &
\end{aligned}
$$

$$
\begin{aligned}
\operatorname{Rank}\left(\tilde{\tilde{v}}_{i j}\right)= & M_{1}\left(\tilde{A}_{i}^{U}\right)+\tilde{M}_{1}\left(\tilde{A}_{i}^{L}\right)+M_{2}\left(\tilde{A}_{i}^{U}\right)+\tilde{M}_{2}\left(\tilde{A}_{i}^{L}\right) \\
& +M_{3}\left(\tilde{A}_{i}^{U}\right)+\tilde{M}_{3}\left(\tilde{A}_{i}^{L}\right)-{ }_{i}-\left(S_{1}\left(\tilde{A}_{i}^{U}\right)+S_{1}\left(\tilde{A}_{i}^{L}\right)\right. \\
& +S_{2}\left(\tilde{A}_{i}^{U}\right)+S_{2}\left(\tilde{A}^{L}\right)+S_{3}\left(\tilde{A}_{i}^{U}\right)+S_{3}\left(\tilde{A}_{i}{ }_{i}\right) \\
& \left.+S_{i}\left(\tilde{A}^{U}\right)+S_{4}\left(\tilde{A}_{i}^{L}\right)\right)+H_{1}\left(\tilde{A}_{i}^{U}\right)+H_{1}\left(\tilde{A}_{i}^{L}\right) \\
& \left.+{ }_{i}\right) \\
& +H_{2}\left(\tilde{A}_{i}^{U}\right)+H_{2}\left(\tilde{A}_{i}^{L}\right) .
\end{aligned}
$$

In the last equation, $M_{p}\left(\tilde{A}_{i}^{j}\right)$ indicates the average of $a_{i p}^{j}$ and $a_{i(p+1)}^{j}$ while $S_{q}\left(\tilde{A}_{i}^{j}\right)$ points out standard deviations of $a_{i 1}^{j}, a_{i 2}^{j}, a_{i 3}^{j}, a_{i 4}^{j}$ and $H_{p}\left(\tilde{A}_{i}^{j}\right)$ expresses the membership values of $a_{i(p+1)}^{j}$ for $1 \leq p \leq 2$, and $1 \leq i \leq n$.

\subsection{Fuzzy TOPSIS Approach by using Interval Type-2 Fuzzy Sets}

In this section, the steps of fuzzy TOPSIS approach using interval Type-2 fuzzy sets are explained briefly as follows: ${ }^{10}$

Step 1: Primarily, the decision matrix $\mathrm{Z}_{\mathrm{s}}$ of $\mathrm{s}^{\text {th }}$ decision maker "Eq. (7)" and the average decision matrix using "Eq. (8)" are constructed. $\tilde{\tilde{f}}_{i j}$ denotes for an interval Type-2 fuzzy $\operatorname{set}(1 \leq i \leq m, 1 \leq j \leq n, 1 \leq s \leq k)$ and $\mathrm{k}$ indicates the number of decision makers.

$$
Z_{s}=\left(\tilde{f}_{i j}^{s}\right)_{m \times n}=\left[\begin{array}{cccc}
\tilde{\tilde{f}}_{11}^{s} & \tilde{\tilde{f}}_{12}^{s} & \cdots & \tilde{\tilde{f}}_{1 n}^{s} \\
\tilde{\tilde{f}}_{21}^{s} & \tilde{\tilde{f}}_{22}^{s} & \cdots & \tilde{\tilde{f}}_{2 n}^{s} \\
\vdots & \vdots & \ddots & \vdots \\
\tilde{\tilde{f}}_{m 1}^{s} & \tilde{\tilde{f}}_{m 2}^{s} & \cdots & \tilde{\tilde{f}}_{m n}^{s}
\end{array}\right]
$$$$
\bar{Z}=\left(\tilde{\tilde{f}}_{i j}\right)_{m \times n}
$$

where

$$
\tilde{\tilde{f}}_{i j}=\left(\frac{\tilde{f}_{i j}^{1} \oplus \tilde{f}_{i j}^{2} \oplus \ldots \oplus \tilde{f}_{i j}^{k}}{k}\right)
$$

Step 2: Once constructing decision matrix $\mathrm{W}_{\mathrm{s}}$ and average decision matrix $\bar{W}$; the weight matrix "Eq. (10)" and average weight matrix by means of "Eq. (11)" are obtained. In the equations shown below, $\tilde{\tilde{w}}_{i}$ represents an interval Type-2 fuzzy set.

$$
\begin{aligned}
& W_{S}=\left(\tilde{\tilde{w}}_{i}^{S}\right)_{1 \times m}=\left[\begin{array}{llll}
\tilde{\tilde{w}}_{1}^{S} & \tilde{\tilde{w}}_{2}^{S} & \ldots & \tilde{\tilde{w}}_{m}^{S}
\end{array}\right], \\
& \bar{W}=\left(\tilde{\tilde{w}}_{i}\right)_{1 \times m} \\
& \tilde{\tilde{w}}_{i}=\left(\frac{\tilde{\tilde{w}}_{i}^{1} \oplus \tilde{\tilde{w}}_{i}^{2} \oplus \ldots \oplus \tilde{\tilde{w}}_{i}^{k}}{k}\right)
\end{aligned}
$$

where $1 \leq i \leq m, 1 \leq \mathrm{j} \leq \mathrm{n}, 1 \leq s \leq k$. 
Step 3: Afterwards, the weighted decision matrix "Eq. (13)" is constructed by employing "Eq. (14)".

$$
\begin{aligned}
& \bar{Z}_{w}=\left(\tilde{\tilde{v}}_{i j}\right)_{m \times n}=\left[\begin{array}{cccc}
\tilde{\tilde{v}}_{11} & \tilde{\tilde{v}}_{12} & \ldots & \tilde{\tilde{v}}_{1 n} \\
\tilde{\tilde{v}}_{21} & \tilde{\tilde{v}}_{22} & \ldots & \tilde{\tilde{v}}_{2 n} \\
\vdots & \vdots & \vdots & \vdots \\
\tilde{\tilde{v}}_{m 1} & \tilde{\tilde{v}}_{m 2} & \ldots & \tilde{\tilde{v}}_{m n}
\end{array}\right] \\
& \tilde{\tilde{v}}_{i j}=\tilde{\tilde{w}}_{i} \otimes \tilde{\tilde{f}}_{i j}
\end{aligned}
$$

where $1 \leq i \leq m, 1 \leq \mathrm{j} \leq \mathrm{n}$.

Step 4: Then, using "Eq. (6)", ranking values "Rank $\left(\tilde{\tilde{v}}_{i j}\right) "$ of interval Type-2 fuzzy set $\tilde{\tilde{v}}_{i j}$ are calculated. Afterwards, ranking weighted decision matrix "Eq. (15)" is constituted.

$$
\bar{Z}_{W}^{*}=\left(\operatorname{Rank}\left(\tilde{\tilde{v}}_{i j}\right)\right)_{m \times n}
$$

where $1 \leq \mathrm{j} \leq \mathrm{n}, 1 \leq i \leq m$.

Step 5: Next, positive ideal solutions $\left[x^{+}=\left(v_{1}^{+}, v_{2}^{+}, \ldots, v_{m}^{+}\right)\right]$and negative ideal solutions $\left[x^{-}=\left(v_{1}^{-}, v_{2}^{-}, \ldots, v_{m}^{-}\right)\right]$are defined. In the equations stated below, $\mathrm{B}$ denotes for benefit criteria as $\mathrm{C}$ presents cost criteria.

$$
\begin{gathered}
v_{i}^{+}=\left\{\begin{array}{l}
\max \left\{\operatorname{Rank}\left(\tilde{\tilde{v}}_{i j}\right)\right\} \text { if } \mathrm{f}_{i} \in B \\
\min \left\{\operatorname{Rank}\left(\tilde{\tilde{v}}_{i j}\right)\right\} \text { if } \mathrm{f}_{i} \in C
\end{array}\right. \\
v_{i}^{-}=\left\{\begin{array}{l}
\min \left\{\operatorname{Rank}\left(\tilde{\tilde{v}}_{i j}\right)\right\} \text { if } \mathrm{f}_{i} \in B \\
\max \left\{\operatorname{Rank}\left(\tilde{\tilde{v}}_{i j}\right)\right\} \text { if } \mathrm{f}_{i} \in C
\end{array}\right.
\end{gathered}
$$

Step 6: Before calculating relative degree of closeness, the distances $\left(d^{+}\left(x_{j}\right), d^{-}\left(x_{j}\right)\right)$ should be calculated. In “Eq. (18)" and "Eq. (19)", $d^{+}\left(x_{j}\right)$ and $d^{-}\left(x_{j}\right)$ represent the distance between each alternative and the positive/negative ideal solutions, relatively.

$$
\begin{aligned}
& d^{+}\left(x_{j}\right)=\sqrt{\sum_{i=1}^{m}\left(\operatorname{Rank}\left(\tilde{\tilde{v}}_{i j}\right)-v_{i}^{+}\right)^{2}} \\
& d^{-}\left(x_{j}\right)=\sqrt{\sum_{i=1}^{m}\left(\operatorname{Rank}\left(\tilde{\tilde{v}}_{i j}\right)-v_{i}^{-}\right)^{2}} .
\end{aligned}
$$

where $1 \leq \mathrm{j} \leq \mathrm{n}$.

Step 7: Then, the relative degree of closeness, $\mathrm{C}\left(\mathrm{x}_{\mathrm{j}}\right)$, is calculated by using "Eq. (20)".

$$
C\left(x_{j}\right)=\frac{d^{-}\left(x_{j}\right)}{d^{+}\left(x_{j}\right)+d^{-}\left(x_{j}\right)}
$$

Step 8: Finally, the values of $\mathrm{C}\left(\mathrm{x}_{\mathrm{j}}\right)$ are ranked according to the ascending order. The higher $\mathrm{C}\left(\mathrm{x}_{\mathrm{j}}\right)$ is the higher the preference.

\section{An Application: Facility Location Selection for a Cement Factory}

\subsection{Problem definition}

Turkish cement industry with its high capacity, product quality, and R\&D, is one of the world's top cement producer and exporter. ${ }^{71}$ The statistics showed that the cement production in Turkey has increased approximately two-fold from $15 \mathrm{~m}$. tons to $30 \mathrm{~m}$. tons since $2000 .^{72}$

This study is based on a facility location selection problem of a company which sets up turnkey cement manufacturing factories in Turkey. The company has been operating over two decades in the sector. The company's service offering to customers includes design of the manufacturing facilities, site selection, building construction, facility layout and material handling systems. However, this study deals with their facility location problem in which the company has to select the best appropriate region among three alternatives and then to select the best appropriate site for the selected region.

\subsection{Solution Procedure}

As stated earlier the model was based on a real life case study of a company to select a suitable location for a cement factory. The model of the study is an extension version of the preliminary study conducted in the company. ${ }^{73}$ The developed model was discussed by the researchers and some criteria were added in order to make the model more robust. Then, the hierarchical models for the region and site selection decisions were evaluated separately by using an MCDM approach with IT2FSs to handle with the high uncertainty in the location selection problem. The evaluation and selection process was conducted with three experts/decision makers having different backgrounds. The region evaluation and selection criteria as well as site selection and evaluation criteria and sub-criteria which have been used in the hierarchies are explained in the following parts. 


\subsubsection{Stage 1: Region evaluation and selection}

The model with three levels is illustrated in Fig. 2. The first level includes the main goal of choosing the most appropriate region. The second level contains six criteria: "Total cost $\left(\mathrm{C}_{1,1}\right)$ ", "Availability of sources $\left(\mathrm{C}_{1,2}\right)$ ", "Strategic factors $\left(\mathrm{C}_{1,3}\right)$ ", "Government policies $\left(\mathrm{C}_{1,4}\right)$ ", "Environmental factors $\left(\mathrm{C}_{1,5}\right)$ " and "Risk factors $\left(\mathrm{C}_{1,6}\right)$ ". Finally, the last level indicates three region alternatives $\left(\mathrm{R}_{1}, \mathrm{R}_{2}\right.$ and $\left.\mathrm{R}_{3}\right)$ determined by the management of the company to establish a cement factory. $^{73}$

Brief explanations of each criterion for the region evaluation and selection process are stated as follows:

Total cost $\left(\mathrm{C}_{1,1}\right)$ : The criterion consists of fixed and variable costs e.g. land cost, transportation cost, raw material cost, energy cost, environmental cost, and insurance. $^{25-74}$

Availability of sources $\left(\mathrm{C}_{1,2}\right)$ : The criterion is related to the availability of the sources such as mines, labor and energy. ${ }^{75-76}$

Strategic factors $\left(C_{1,3}\right)$ : The criterion pertains the competitiveness within the region such as the sales of competitors, market size and expansion opportunities. ${ }^{77}$

Government policies $\left(\mathrm{C}_{1,4}\right)$ : The criterion indicates taxes, incentives/financial supports, licenses and trade policies for the region alternatives. ${ }^{25-76-77}$

Environmental factors $\left(\mathrm{C}_{1,5}\right)$ : The criterion implicates the climate, habitat, protected animal species and flora in the regions. ${ }^{71-78}$

Risk factors $\left(\mathrm{C}_{1,6}\right)$ : The criterion points out a various risks associated with global risks, financial risks and terror risks.

Considering the hierarchical model, decision makers were asked to indicate their judgments for the criteria and the decision alternatives. Linguistic expressions and their corresponding interval Type-2 fuzzy sets $^{79}$ presented in Table 1 and Table 2, were employed during the evaluations.

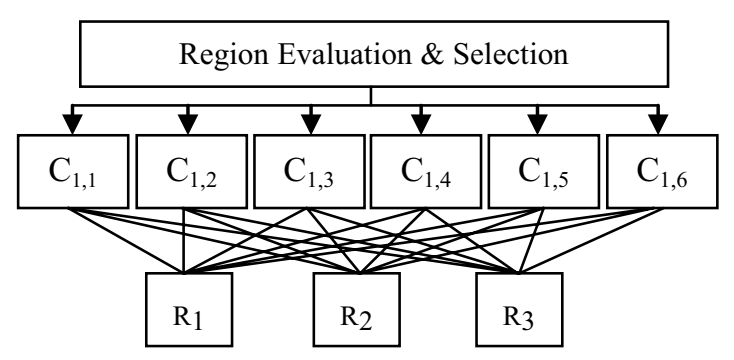

Fig. 2. Hierarchy for the region evaluation and selection
Table 1. Linguistic weights and corresponding IT2FSs ${ }^{79}$

\begin{tabular}{ll}
\hline Linguistic terms & Interval Type-2 fuzzy sets \\
\hline Very Low (VL) & $((0,0,0,0.1 ; 1,1),(0,0,0,0.1 ; 1,1))$ \\
Low (L) & $(0,0.1,0.1,0.3 ; 1,1),(0,0.1,0.1,0.3 ; 1,1))$ \\
Medium Low (ML) & $((0.1,0.3,0.3,0.5 ; 1,1),(0.1,0.3,0.3,0.5 ; 1,1))$ \\
Medium (M) & $((0.3,0.5,0.5,0.7 ; 1,1),(0.3,0.5,0.5,0.7 ; 1,1))$ \\
Medium High (MH) & $((0.5,0.7,0.7,0.9 ; 1,1),(0.5,0.7,0.7,0.9 ; 1,1))$ \\
High (H) & $((0.7,0.9,0.9,1 ; 1,1),(0.7,0.9,0.9,1 ; 1,1))$ \\
Very High (VH) & $((0.9,1,1,1 ; 1,1),(0.9,1,1,1 ; 1,1))$ \\
\hline
\end{tabular}

Table 2. Linguistic ratings and corresponding IT2FSs ${ }^{79}$

\begin{tabular}{ll}
\hline Linguistic terms & Interval Type-2 fuzzy sets \\
\hline Very Poor (VP) & $((0,0,0,1 ; 1,1),(0,0,0,1 ; 1,1))$ \\
Poor (P) & $((0,1,1,3 ; 1,1),(0,1,1,3 ; 1,1))$ \\
Medium Poor (MP) & $((1,3,3,5 ; 1,1),(1,3,3,5 ; 1,1))$ \\
Medium (M) & $((3,5,5,7 ; 1,1),(3,5,5,7 ; 1,1))$ \\
Medium Good(MG) & $((5,7,7,9 ; 1,1),(5,7,7,9 ; 1,1))$ \\
Good (G) & $((7,9,9,10 ; 1,1),(7,9,9,10 ; 1,1))$ \\
Very Good (VG) & $((9,10,10,10 ; 1,1),(9,10,10,10 ; 1,1))$ \\
\hline
\end{tabular}

In the analysis for both of the stages, all the criteria are treated as benefit criteria and by reversing assigned values depending on the linguistic scale, cost criteria are converted into benefit criteria. In Table 3, evaluations of the weights of criteria are represented while the linguistic expressions used for comparison of the alternatives with respect to criteria are collected and listed in Table 4.

Table 3. Evaluation of the weights of criteria

\begin{tabular}{c|ccc}
\hline Criteria & $\mathrm{DM}_{1}$ & $\mathrm{DM}_{2}$ & $\mathrm{DM}_{3}$ \\
\hline $\mathrm{C}_{1,1}$ & $\mathrm{ML}$ & $\mathrm{L}$ & $\mathrm{L}$ \\
$\mathrm{C}_{1,2}$ & $\mathrm{M}$ & $\mathrm{ML}$ & $\mathrm{ML}$ \\
$\mathrm{C}_{1,3}$ & $\mathrm{MH}$ & $\mathrm{MH}$ & $\mathrm{M}$ \\
$\mathrm{C}_{1,4}$ & $\mathrm{~L}$ & $\mathrm{VL}$ & $\mathrm{VL}$ \\
$\mathrm{C}_{1,5}$ & $\mathrm{H}$ & $\mathrm{M}$ & $\mathrm{MH}$ \\
$\mathrm{C}_{1,6}$ & $\mathrm{VH}$ & $\mathrm{H}$ & $\mathrm{H}$ \\
\hline
\end{tabular}

Table 4. Evaluation of alternatives with respect to DMs

\begin{tabular}{c|c|ccc}
\hline Criteria & Regions & $\mathrm{DM}_{1}$ & $\mathrm{DM}_{2}$ & $\mathrm{DM}_{3}$ \\
\hline \multirow{3}{*}{$\mathrm{C}_{1,1}$} & $\mathrm{R}_{1}$ & $\mathrm{P}$ & $\mathrm{MP}$ & $\mathrm{P}$ \\
& $\mathrm{R}_{2}$ & $\mathrm{MP}$ & $\mathrm{P}$ & $\mathrm{M}$ \\
& $\mathrm{R}_{3}$ & $\mathrm{P}$ & $\mathrm{MP}$ & $\mathrm{MP}$ \\
\hline \multirow{3}{*}{$\mathrm{C}_{1,2}$} & $\mathrm{R}_{1}$ & $\mathrm{VG}$ & $\mathrm{G}$ & $\mathrm{VG}$ \\
& $\mathrm{R}_{2}$ & $\mathrm{G}$ & $\mathrm{M}$ & $\mathrm{MG}$ \\
& $\mathrm{R}_{3}$ & $\mathrm{M}$ & $\mathrm{MG}$ & $\mathrm{M}$ \\
\hline \multirow{3}{*}{$\mathrm{C}_{1,3}$} & $\mathrm{R}_{1}$ & $\mathrm{G}$ & $\mathrm{G}$ & $\mathrm{M}$ \\
& $\mathrm{R}_{2}$ & $\mathrm{M}$ & $\mathrm{M}$ & $\mathrm{MP}$ \\
& $\mathrm{R}_{3}$ & $\mathrm{P}$ & $\mathrm{MP}$ & $\mathrm{P}$ \\
\hline \multirow{3}{*}{$\mathrm{C}_{1,4}$} & $\mathrm{R}_{1}$ & $\mathrm{M}$ & $\mathrm{G}$ & $\mathrm{M}$ \\
& $\mathrm{R}_{2}$ & $\mathrm{MG}$ & $\mathrm{MG}$ & $\mathrm{G}$ \\
& $\mathrm{R}_{3}$ & $\mathrm{M}$ & $\mathrm{MG}$ & $\mathrm{MG}$ \\
\hline \multirow{3}{*}{$\mathrm{C}_{1,5}$} & $\mathrm{R}_{1}$ & $\mathrm{P}$ & $\mathrm{P}$ & $\mathrm{MP}$ \\
& $\mathrm{R}_{2}$ & $\mathrm{MP}$ & $\mathrm{MP}$ & $\mathrm{P}$ \\
& $\mathrm{R}_{3}$ & $\mathrm{M}$ & $\mathrm{M}$ & $\mathrm{MP}$ \\
\hline \multirow{3}{*}{$\mathrm{C}_{1,6}$} & $\mathrm{R}_{1}$ & $\mathrm{P}$ & $\mathrm{VP}$ & $\mathrm{P}$ \\
& $\mathrm{R}_{2}$ & $\mathrm{MP}$ & $\mathrm{M}$ & $\mathrm{MP}$ \\
& $\mathrm{R}_{3}$ & $\mathrm{P}$ & $\mathrm{P}$ & $\mathrm{P}$ \\
\hline
\end{tabular}


After obtaining comparisons of the regions according to each criterion for each decision maker, the decision matrix is obtained by using "Eq. (7)".

$Z_{1}=\left[\begin{array}{ccc}P & M P & P \\ V G & G & M \\ G & M & P \\ M & M G & M \\ P & M P & M \\ P & M P & P\end{array}\right], Z_{2}=\left[\begin{array}{ccc}M P & P & M P \\ G & M & M G \\ G & M & M P \\ G & M G & M G \\ P & M P & M \\ V P & M & P\end{array}\right], Z_{3}=\left[\begin{array}{ccc}P & M & M P \\ V G & M G & M \\ M & M P & P \\ M & G & M G \\ M P & P & M P \\ P & M P & P\end{array}\right]$

Once the decision matrices are obtained, the average decision matrix is constructed. To construct average matrix, each $\tilde{\tilde{f}}_{i j}$ is calculated by "Eq. (9)" and the calculated values are normalized by dividing the findings to ' 10 '. The calculations are displayed below.

$$
\begin{aligned}
& \tilde{\tilde{f}}_{11}=((0.03,0.17,0.17,0.37 ; 1,1),(0.03,0.17,0.17,0.37 ; 1,1)) \\
& \tilde{\tilde{f}}_{12}=((0.13,0.30,0.30,0.50 ; 1,1),(0.13,0.30,0.30,0.50 ; 1,1)) \\
& \tilde{\tilde{f}}_{13}=((0.07,0.23,0.23,0.43 ; 1,1),(0.07,0.23,0.23,0.43 ; 1,1)) \\
& \tilde{\tilde{f}}_{21}=((0.83,0.97,0.97,1 ; 1,1),(0.83,0.97,0.97,1 ; 1,1)) \\
& \left.\tilde{\tilde{f}}_{22}=((0.50,0.70,0.70,0.87 ; 1,1), 0.50,0.70,0.70,0.87 ; 1,1)\right) \\
& \tilde{\tilde{f}}_{23}=((0.37,0.57,0.57,0.77 ; 1,1),(0.37,0.57,0.57,0.77 ; 1,1)) \\
& \tilde{\tilde{f}}_{31}=((0.57,0.77,0.77,0.90 ; 1,1),((0.57,0.77,0.77,0.90 ; 1,1)) \\
& \tilde{\tilde{f}}_{32}=((0.23,0.43,0.43,0.63 ; 1,1),(0.23,0.43,0.43,0.63 ; 1,1)) \\
& \tilde{\tilde{f}}_{33}=((0.03,0.17,0.17,0.37 ; 1,1),(0.03,0.17,0.17,0.37 ; 1,1)) \\
& \tilde{\tilde{f}}_{41}=((0.43,0.63,0.63,0.80 ; 1,1),(0.43,0.63,0.63,0.80 ; 1,1)) \\
& \tilde{\tilde{f}}_{42}=((0.57,0.77,0.77,0.93 ; 1,1),((0.57,0.77,0.77,0.93 ; 1,1)) \\
& \tilde{\tilde{f}}_{43}=((0.43,0.63,0.63,0.83 ; 1,1),(0.43,0.63,0.63,0.83 ; 1,1)) \\
& \tilde{\tilde{f}}_{51}=((0.03,0.17,0.17,0.37 ; 1,1),(0.03,0.17,0.17,0.37 ; 1,1)) \\
& \tilde{\tilde{f}}_{52}=((0.07,0.23,0.23,0.43 ; 1,1),(0.07,0.23,0.23,0.43 ; 1,1)) \\
& \tilde{\tilde{f}}_{53}=((0.23,0.43,0.43,0.63 ; 1,1),(0.23,0.43,0.43,0.63 ; 1,1)) \\
& \tilde{\tilde{f}}_{61}=((0,0.07,0.07,0.23 ; 1,1),(0,0.07,0.07,0.23 ; 1,1)) \\
& \tilde{\tilde{f}}_{62}=((0.17,0.37,0.37,0.57 ; 1,1),(0.17,0.37,0.37,0.57 ; 1,1)) \\
& \tilde{\tilde{f}}_{63}=((0,0.10,0.10,0.30 ; 1,1),(0,0.10,0.10,0.30 ; 1,1))
\end{aligned}
$$

Then, for each criterion the weight matrix $\bar{W}=\left[\begin{array}{lllllll}\tilde{\tilde{w}}_{1} & \tilde{\tilde{w}}_{2} & \tilde{w}_{3} & \tilde{\tilde{w}}_{4} & \tilde{\tilde{w}}_{5} & \tilde{\tilde{w}}_{6} & \tilde{\tilde{w}}_{7}\end{array}\right] \quad$ is obtained by calculating each fuzzy weight. The results are:

$$
\begin{aligned}
& \tilde{w}_{1}=((0.03,0.17,0.17,0.37 ; 1,1),(0.03,0.17,0.17,0.37 ; 1,1)) \\
& \tilde{w}_{2}=((0.17,0.37,0.37,0.57 ; 1,1),(0.17,0.37,0.37,0.57 ; 1,1)) \\
& \tilde{w}_{3}=((0.43,0.63,0.63,0.83 ; 1,1),(0.43,0.63,0.63,0.83 ; 1,1)) \\
& \tilde{w}_{4}=((0,0.03,0.03,0.15 ; 1,1),(0,0.03,0.03,0.15 ; 1,1)) \\
& \tilde{w}_{5}=((0.50,0.70,0.70,0.87 ; 1,1),(0.50,0.70,0.70,0.87 ; 1,1)) \\
& \tilde{w}_{6}=((0.77,0.93,0.93,1 ; 1,1),(0.77,0.93,0.93,1 ; 1,1))
\end{aligned}
$$

After obtaining fuzzy weights and the fuzzy decision matrix, the weighted decision matrix as symbolized $\bar{Z}_{w}$ is calculated ("Eq. (13)"). The calculations are given below:

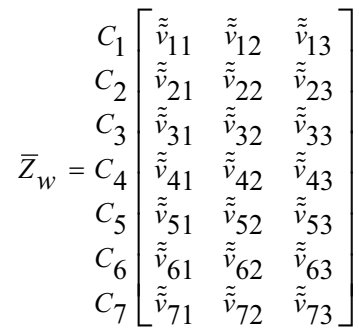

$\tilde{\tilde{v}}_{11}=((0,0.03,0.03,0.13 ; 1,1),(0,0.03,0.03,0.13 ; 1,1))$

$\tilde{\tilde{v}}_{12}=((0,0.05,0.05,0.18 ; 1,1),(0,0.05,0.05,0.18 ; 1,1))$

$\tilde{\tilde{v}}_{13}=((0,0.04,0.04,0.16 ; 1,1),(0,0.04,0.04,0.16 ; 1,1))$

$\tilde{\tilde{v}}_{21}=((0.14,0.35,0.35,0.57 ; 1,1),(0.14,0.35,0.35,0.57 ; 1,1))$

$\tilde{\tilde{v}}_{22}=((0.08,0.26,0.26,0.49 ; 1,1),(0.08,0.26,0.26,0.49 ; 1,1))$

$\tilde{\tilde{v}}_{23}=((0.06,0.21,0.21,0.43 ; 1,1),(0.06,0.21,0.21,0.43 ; 1,1))$

$\tilde{\tilde{v}}_{31}=((0.25,0.49,0.49,0.75 ; 1,1),(0.25,0.49,0.49,0.75 ; 1,1))$

$\tilde{\tilde{v}}_{32}=((0.10,0.27,0.27,0.53 ; 1,1),(0.10,0.27,0.27,0.53 ; 1,1))$

$\tilde{\tilde{v}}_{33}=((0.01,0.11,0.11,0.31 ; 1,1),(0.01,0.11,0.11,0.31 ; 1,1))$

$\tilde{\tilde{v}}_{41}=((0.22,0.44,0.44,0.69 ; 1,1),(0.22,0.44,0.44,0.69 ; 1,1))$

$\tilde{\tilde{v}}_{42}=((0.28,0.54,0.54,0.81 ; 1,1),(0.28,0.54,0.54,0.81 ; 1,1))$

$\tilde{\tilde{v}}_{43}=((0.28,0.54,0.54,0.81 ; 1,1),(0.28,0.54,0.54,0.81 ; 1,1))$

$\tilde{\tilde{v}}_{51}=((0.03,0.16,0.16,0.37 ; 1,1),(0.03,0.16,0.16,0.37 ; 1,1))$

$\tilde{\tilde{v}}_{52}=((0.05,0.22,0.22,0.43 ; 1,1),(0.05,0.22,0.22,0.43 ; 1,1))$

$\tilde{\tilde{v}}_{53}=((0.18,0.40,0.40,0.63 ; 1,1),(0.18,0.40,0.40,0.63 ; 1,1))$

$\tilde{\tilde{v}}_{61}=((0,0.06,0.06,0.23 ; 1,1),(0,0.06,0.06,0.23 ; 1,1))$

$\tilde{\tilde{v}}_{62}=((0.14,0.35,0.35,0.57 ; 1,1),(0.14,0.35,0.35,0.57 ; 1,1))$

$\tilde{\tilde{v}}_{63}=((0,0.10,0.10,0.30 ; 1,1),(0,0.10,0.10,0.30 ; 1,1))$

Then, as the next step the weighted decision matrix $\left(\bar{Z}_{w}^{*}\right)$ for rankings is obtained using "Eq. (15)".

$$
\begin{aligned}
& C_{1,1}\left[\operatorname{Rank}\left(\tilde{\tilde{v}}_{11}\right) \quad \operatorname{Rank}\left(\tilde{\tilde{v}}_{12}\right) \quad \operatorname{Rank}\left(\tilde{\tilde{v}}_{13}\right)\right] \\
& C_{1,2} \operatorname{Rank}\left(\tilde{\tilde{v}}_{21}\right) \operatorname{Rank}\left(\tilde{\tilde{v}}_{22}\right) \operatorname{Rank}\left(\tilde{\tilde{v}}_{23}\right)
\end{aligned}
$$

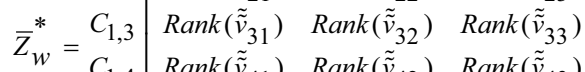

$$
\begin{aligned}
& \begin{array}{l|lll}
C_{1,4} & \operatorname{Rank}\left(\tilde{\tilde{v}}_{41}\right) & \operatorname{Rank}\left(\tilde{\tilde{v}}_{42}\right) & \operatorname{Rank}\left(\tilde{\tilde{v}}_{43}\right) \\
C_{1,5} & \operatorname{Rank}\left(\tilde{\tilde{v}}_{51}\right) & \operatorname{Rank}\left(\tilde{\tilde{v}}_{52}\right) & \operatorname{Rank}\left(\tilde{\tilde{v}}_{53}\right)
\end{array} \\
& \begin{array}{l|lll}
C_{1,6} & \operatorname{Rank}\left(\tilde{\tilde{v}}_{61}\right) & \operatorname{Rank}\left(\tilde{\tilde{v}}_{62}\right) & \operatorname{Rank}\left(\tilde{v}_{63}\right)
\end{array} \\
& \bar{Z}_{w}^{*}=\left[\begin{array}{ccc}
4.19 & 4.31 & 4.25 \\
5.94 & 5.43 & 5.17 \\
6.72 & 5.54 & 4.62 \\
6.48 & 7.01 & 6.50 \\
4.87 & 5.19 & 6.24 \\
4.39 & 5.94 & 4.56
\end{array}\right]
\end{aligned}
$$

As an example, the calculation of $\operatorname{Rank}\left(\tilde{\tilde{v}}_{11}\right)$ is found by using "Eq. (6)" and explained as follows: 


$$
\begin{aligned}
\operatorname{Rank}\left(\tilde{\tilde{v}}_{i j}\right)= & M_{1}\left(\tilde{v}_{11}^{U}\right)+\tilde{M}_{1}\left(\tilde{v}_{11}^{L}\right)+M_{2}\left(\tilde{v}_{11}^{U}\right)+\tilde{M}_{2}\left(\tilde{v}_{11}^{L}\right) \\
& +M_{3}\left(\tilde{v}_{11}^{U}\right)+\tilde{M}_{3}\left(\tilde{v}_{11}^{L}\right)-\frac{1}{4}\left(S_{1}\left(\tilde{v}_{11}^{U}\right)+S_{1}\left(\tilde{v}_{11}^{L}\right)\right. \\
& +S_{2}\left(\tilde{v}_{11}^{U}\right)+S_{2}\left(\tilde{v}_{11}^{L}\right)+S_{3}\left(\tilde{v}_{11}^{U}\right)+S_{3}\left(\tilde{v}_{11}^{L}\right) \\
& \left.+S_{4}\left(\tilde{v}_{11}^{U}\right)+S_{4}\left(\tilde{v}_{11}^{L}\right)\right)+H_{1}\left(\tilde{v}_{11}^{U}\right)+H_{1}\left(\tilde{v}_{11}^{L}\right) \\
& +H_{2}\left(\tilde{v}_{11}^{U}\right)+H_{2}\left(\tilde{v}_{11}^{L}\right) \\
\operatorname{Rank}\left(\tilde{\tilde{v}}_{11}\right)= & 0.25-0.06+4=4.19
\end{aligned}
$$

Once ranking values are obtained, positive ideal solutions (PIS) and negative ideal solutions (NIS) are derived by "Eq. (16)" and Eq. "(17)". The formulation of positive ideal solution is illustrated in "Eq. (26)". The findings are shown in "Eq. (27)" and Eq. "(28)".

$$
\begin{aligned}
x^{+}= & {\left[\max \left(\operatorname{Rank}\left(\tilde{\tilde{v}}_{11}\right), \operatorname{Rank}\left(\tilde{\tilde{v}}_{12}\right), \operatorname{Rank}\left(\tilde{\tilde{v}}_{13}\right)\right), \mathrm{max}\left(\operatorname{Rank}\left(\tilde{\tilde{v}}_{21}\right),\right.\right.} \\
& \left.\operatorname{Rank}\left(\tilde{\tilde{v}}_{22}\right), \operatorname{Rank}\left(\tilde{v}_{23}\right)\right), \max \left(\operatorname{Rank}\left(\tilde{\tilde{v}}_{31}\right), \operatorname{Rank}\left(\tilde{\tilde{v}}_{32}\right),\right. \\
& \left.\operatorname{Rank}\left(\tilde{\tilde{v}}_{33}\right)\right), m \operatorname{ax}\left(\operatorname{Rank}\left(\tilde{\tilde{v}}_{41}\right), \operatorname{Rank}\left(\tilde{\tilde{v}}_{42}\right), \operatorname{Rank}\left(\tilde{\tilde{v}}_{43}\right)\right), \\
& m \operatorname{ax}\left(\operatorname{Rank}\left(\tilde{v}_{51}\right), \operatorname{Rank}\left(\tilde{\tilde{v}}_{52}\right), \operatorname{Rank}\left(\tilde{\tilde{v}}_{53}\right)\right), \max \left(\operatorname{Rank}\left(\tilde{\tilde{v}}_{61}\right),\right. \\
& \left.\left.\operatorname{Rank}\left(\tilde{\tilde{v}}_{62}\right), \operatorname{Rank}\left(\tilde{\tilde{v}}_{63}\right)\right)\right] \\
x^{+}= & {[4.31,5.94,6.72,7.01,6.24,4.39] } \\
x^{-}= & {[4.19,5.17,4.62,6.48,4.87,5.94] }
\end{aligned}
$$

Based on positive and negative ideal solutions obtained in the previous step, distances from each alternative and PIS or NIS values are computed. Afterwards, calculated distances are used in order to find the relative degree of closeness $\left(\mathrm{C}\left(\mathrm{x}_{\mathrm{i}}\right)\right)$ by "Eq. (20)".

$$
\begin{aligned}
& d^{+}\left(x_{1}\right)=\sqrt{\sum_{i=1}^{6}\left(\operatorname{Rank}\left(\tilde{\tilde{v}}_{i 1}\right)-v_{i}^{+}\right)^{2}}=1.47, \\
& d^{-}\left(x_{1}\right)=\sqrt{\sum_{i=1}^{6}\left(\operatorname{Rank}\left(\tilde{\tilde{v}}_{i 1}\right)-v_{i}^{-}\right)^{2}}=2.73, \\
& d^{+}\left(x_{2}\right)=2.27, \\
& d^{-}\left(x_{2}\right)=1.16, \\
& d^{+}\left(x_{3}\right)=2.31, \\
& d^{-}\left(x_{3}\right)=1.95 . \\
& C\left(x_{1}\right)=\frac{d^{-}\left(x_{1}\right)}{d^{-}\left(x_{1}\right)+d^{+}\left(x_{1}\right)}=0.65, \\
& C\left(x_{2}\right)=0.34 \\
& C\left(x_{3}\right)=0.46 . \\
& C\left(x_{1}\right) \geq C\left(x_{3}\right) \geq C\left(x_{2}\right)
\end{aligned}
$$

When the values of the relative degree of closeness are ranked in the ascending order ("Eq. (31)"), the results reveals that Region 1 is the best appropriate region for establishing a cement factory and it is followed by Region 3 and Region 2 sequentially.

\subsubsection{Stage 2: Site evaluation and selection}

The hierarchical model of site evaluation and selection consists of four levels. The top level includes the main goal of selecting the best appropriate site. The second level introduces six criteria. The third level presents sub-criteria while the last level indicates alternative sites for the chosen region in the previous stage. The criteria and sub-criteria of the model are illustrated in Table 5 and defined as follows:

Earth Sciences $\left(\mathrm{C}_{2,1}\right)$ : The criterion includes several sub-criteria which are mainly geomorphology, geophysical, topographic and tectonic structure as well as seismic structure of the site alternatives. ${ }^{78-80}$

Geomorphological structure $\left(\mathrm{C}_{2,11}\right)$ : The subcriterion is related to the earth shapes, the change of earth shapes and the formation processes. ${ }^{81}$

Geophysical structure $\left(\mathrm{C}_{2,12}\right)$ : This sub-criterion considers mainly the invisible deep inner structure of Earth. ${ }^{82}$ In this case, it is related to the thickness and the depth of the bedrock.

Topographic structure $\left(\mathrm{C}_{2,13}\right)$ : The sub-criterion includes the visible outer structure of Earth and it gives the detailed description about the feature of the surface such as hills, and valleys. ${ }^{83}$

Tectonic structure $\left(\mathrm{C}_{2,14}\right)$ : This sub-criterion is about the invisible inner structure of Earth such as the crustal fragmentation of the earth's bedrock.

Seismic structure $\left(\mathrm{C}_{2,15}\right)$ : The sub-criterion is briefly associated with the magmatic processes.

Characteristics of Raw Material $\left(\mathrm{C}_{2,2}\right)$ : The criterion includes the characteristics of raw material such as reserve capacity, reserve quality, proximity to surface and sustainability of the raw material which are necessary for sustainability of the cement production, and indicates the chemical specifications of cement and the mineralogy of available materials mainly for limestone, clay and marl. ${ }^{84-85}$

Infrastructure System $\left(\mathrm{C}_{2,3}\right)$ : The criterion includes two sub-criteria which are "Utility" and "Energy". The primer is related to utilities e.g. electricity, water, heat, communication and waste disposal systems. ${ }^{80}$ The last is about energy sources, mainly coal and natural gas or electrical energy. ${ }^{84}$ 
Table 5. Criteria and sub-criteria for Stage 2

\begin{tabular}{|c|c|}
\hline Criteria & Sub-criteria \\
\hline \multirow{5}{*}{$\begin{array}{c}\mathrm{C}_{2,1}: \\
\text { Earth Sciences }\end{array}$} & $\mathrm{C}_{2,11}$ : Geomorphologic structure \\
\hline & $\mathrm{C}_{2,12}$ : Geophysical structure \\
\hline & $\mathrm{C}_{2,13}$ : Topographic structure \\
\hline & $\mathrm{C}_{2,14}$ : Tectonic structure \\
\hline & $\mathrm{C}_{2,15}$ : Seismic structure \\
\hline \multirow{4}{*}{$\begin{array}{c}\mathrm{C}_{2,2}: \\
\text { Characteristics of } \\
\text { Raw Material }\end{array}$} & $\mathrm{C}_{2,21}$ : Reserve capacity \\
\hline & $\mathrm{C}_{2,22}$ : Quality \\
\hline & $\mathrm{C}_{2,23}$ : Sustainability of raw material \\
\hline & $\mathrm{C}_{2,24}$ : Proximity to surface \\
\hline \multirow{2}{*}{$\begin{array}{c}\mathrm{C}_{2,3}: \\
\text { Infrastructure }\end{array}$} & $\mathrm{C}_{2,31}$ : Utilities \\
\hline & $\mathrm{C}_{2,32}$ : Energy \\
\hline \multirow{3}{*}{$\begin{array}{c}\mathrm{C}_{2,4}: \\
\text { Social Factors }\end{array}$} & $\mathrm{C}_{2,41}:$ Population \\
\hline & $\mathrm{C}_{2,42}$ : Local support \\
\hline & $\mathrm{C}_{2,43}$ : Contribution to society \\
\hline \multirow{6}{*}{$\begin{array}{l}\quad \mathrm{C}_{2,5}: \\
\text { Transportation } \\
\text { and Distances }\end{array}$} & $\mathrm{C}_{2,51}$ : Distance to transportation vehicles \\
\hline & $\mathrm{C}_{2,52}$ : Potential highways \\
\hline & $\mathrm{C}_{2,53}$ : Accessibility \\
\hline & $\mathrm{C}_{2,54}$ : Closeness to mines \\
\hline & $\mathrm{C}_{2,55}$ : Distances from the nearest villages \\
\hline & $\mathrm{C}_{2,56}$ : Distances from the historical sites \\
\hline \multirow{2}{*}{$\begin{array}{l}\mathrm{C}_{2,6}: \\
\text { Labor }\end{array}$} & $\mathrm{C}_{2,61}$ : Availability of blue-collar \\
\hline & $\mathrm{C}_{2,62}$ : Availability of white-collar \\
\hline
\end{tabular}

Social Factors $\left(\mathrm{C}_{2,4}\right)$ : The criterion includes socio structure of the site alternatives, and has three subcriteria which are "Population", "Local Support", and "Contribution to the society".

Transportation and Distances $\left(\mathrm{C}_{2,5}\right)$ : The criterion defines the current state of the transportation vehicles, the construction potential of highways, accessibility, distances to the nearest villages, to the mines, and to the historical sites. ${ }^{80-86}$

Labor $\left(\mathrm{C}_{2,6}\right)$ : The criterion defines the potential of blue-collar and white-collar employees for each site alternatives.

The same approach is also employed to evaluate the alternative sites in Stage 2. By using similar evaluation processes conducted in the previous stage, the decision matrix, the average normalized decision matrix and the weight matrix are obtained starting from the last level of the hierarchy. Then, obtained values are multiplied with related fuzzy weights so that the weighted decision matrix is found. As a next step, all fuzzy weighted decision matrices are aggregated for the upper levels of the hierarchy. Then, sequentially, the ranking scores are calculated and shown in the matrix of $\bar{Z}_{w}^{*}$.

$$
\begin{aligned}
& \bar{Z}_{w}^{*}=\left[\begin{array}{ccccc}
\operatorname{Rank}\left(\tilde{\tilde{v}}_{11}\right) & \operatorname{Rank}\left(\tilde{\tilde{v}}_{12}\right) & \cdots & \operatorname{Rank}\left(\tilde{\tilde{v}}_{17}\right) \\
\operatorname{Rank}\left(\tilde{\tilde{v}}_{21}\right) & \operatorname{Rank}\left(\tilde{\tilde{v}}_{22}\right) & \cdots & \operatorname{Rank}\left(\tilde{\tilde{v}}_{27}\right) \\
\vdots & \vdots & \ddots & \vdots \\
\operatorname{Rank}\left(\tilde{\tilde{v}}_{61}\right) & \operatorname{Rank}\left(\tilde{\tilde{v}}_{62}\right) & \cdots & \operatorname{Rank}\left(\tilde{\tilde{v}}_{67}\right)
\end{array}\right] \\
& \bar{Z}_{w}^{*}=\left[\begin{array}{cccccccc}
6.73 & 7.87 & 7.41 & 10.14 & 7.71 & 6.99 & 5.90 \\
10.68 & 12.03 & 11.05 & 14.95 & 8.85 & 8.57 & 7.29 \\
4.99 & 5.78 & 5.16 & 6.84 & 5.16 & 5.05 & 4.90 \\
4.40 & 4.77 & 4.91 & 5.78 & 4.96 & 5.02 & 5.10 \\
7.89 & 7.68 & 9.88 & 12.64 & 7.55 & 7.53 & 5.62 \\
4.07 & 4.25 & 4.10 & 4.32 & 4.18 & 4.17 & 4.19
\end{array}\right]
\end{aligned}
$$

Afterwards, positive and negative ideal solutions are calculated. By employing PIS and NIS values, distances between PIS/NIS and each alternative are found and illustrated in Table 6 . In Table 6, the relative degree of closeness values are also represented.

$$
\begin{aligned}
& x^{+}=[10.14,14.95,6.84,5.78,12.64,4.32] \\
& x^{-}=[5.90,7.29,4.90,4.40,5.62,4.07]
\end{aligned}
$$

Table 6. Distances and relative degree of closeness values

$$
\begin{array}{lll}
d^{+}\left(S_{1}\right)=7.60 & d^{-}\left(S_{1}\right)=4.17 & C\left(S_{1}\right)=0.35 \\
d^{+}\left(S_{2}\right)=6.36 & d^{-}\left(S_{2}\right)=5.62 & C\left(S_{2}\right)=0.47 \\
d^{+}\left(S_{3}\right)=5.82 & d^{-}\left(S_{3}\right)=5.91 & C\left(S_{3}\right)=0.50 \\
d^{+}\left(S_{4}\right)=11.78 & d^{-}\left(S_{4}\right)=12.55 & C\left(S_{4}\right)=0.52 \\
d^{+}\left(S_{5}\right)=11.34 & d^{-}\left(S_{5}\right)=4.50 & C\left(S_{5}\right)=0.28 \\
d^{+}\left(S_{6}\right)=11.68 & d^{-}\left(S_{6}\right)=4.15 & C\left(S_{6}\right)=0.26 \\
d^{+}\left(S_{7}\right)=12.41 & d^{-}\left(S_{7}\right)=2.22 & C\left(S_{7}\right)=0.15
\end{array}
$$

From Table 6, the ranking order of the relative degree of closeness values is found as:

$C\left(S_{4}\right) \geq C\left(S_{3}\right) \geq C\left(S_{2}\right) \geq C\left(S_{1}\right) \geq C\left(S_{5}\right) \geq C\left(S_{6}\right) \geq C\left(S_{7}\right)$.

That means Site 4 is the best appropriate site for establishing a cement factory in Region 1 and it is sequentially followed by Site 3 and Site 2 . The lowest value is found for Site 7 . 


\section{Comparison}

To analyze the results of the robustness, the application results with fuzzy Type-2 fuzzy sets are compared with the findings obtained from the application of other multi-criteria decision making approaches to the multistage and multi-criteria facility location selection problem. One of the approaches to be compared was to integrate Buckley's fuzzy $\mathrm{AHP}^{87}$ and fuzzy VIKOR methods using Type-1 fuzzy sets. The other one was an integrated approach using Type-1 fuzzy sets in which the criteria weights obtained from Zeng's fuzzy AHP ${ }^{88}$ were used in fuzzy VIKOR method to evaluate and rank the alternatives. ${ }^{73}$ The next one is to solve the problem by using fuzzy TOPSIS method with Type-1 fuzzy sets.

In this section, the weights of decision makers (DMs) are also changed; and the problem is resolved several times by employing Zeng's fuzzy AHP integrated with fuzzy VIKOR approach.

The solutions to the problem from all of the approaches for the region evaluation \& selection decision give the similar results. So that Region 1 is the best region taking the highest score and it is followed by Region 3 and Region 2, respectively.

The same approaches are applied for the site evaluation and selection problem. However, different rankings of the alternatives are derived depending on the chosen approach. However, each approach has emphasized that S4 is the best appropriate site within Region 1 to construct a cement factory. The results of the approaches for the site selection decision are comparatively listed and illustrated in Table 7.

Table 7. Summary of comparison results for sites

\begin{tabular}{|c|c|c|c|c|c|c|c|}
\hline Methods & $\mathrm{S} 1$ & $\mathrm{~S} 2$ & S3 & S4 & S5 & S6 & S7 \\
\hline $\begin{array}{l}\text { Proposed approach } \\
\text { (Type-2) }\end{array}$ & 4 & 3 & 2 & 1 & 5 & 6 & 7 \\
\hline $\begin{array}{l}\text { Buckley's fuzzy AHP } \\
\text { integrated with fuzzy } \\
\text { VIKOR (Type-1) }\end{array}$ & 4 & 3 & 2 & 1 & 5 & 6 & 7 \\
\hline Fuzzy TOPSIS (Type-1) & 3 & 4 & 1 & 2 & 5 & 6 & 7 \\
\hline \multicolumn{8}{|c|}{ Zeng's fuzzy AHP integrated with fuzzy VIKOR (Type-1) } \\
\hline DMs' weights & $\mathrm{S} 1$ & $\mathrm{~S} 2$ & S3 & S4 & S5 & S6 & S7 \\
\hline$(0.33-0.33-0.33)$ & 3 & 2 & 4 & 1 & 5 & 6 & 7 \\
\hline$(0.60-0.20-0.20)$ & 4 & 2 & 5 & 1 & 3 & 6 & 7 \\
\hline$(0.10-0.30-0.60)$ & 3 & 2 & 5 & 1 & 4 & 6 & 7 \\
\hline$(0.35-0.50-0.15)$ & 3 & 2 & 5 & 1 & 4 & 6 & 7 \\
\hline
\end{tabular}

\section{Conclusion Remarks \& Future Suggestions}

Facility location selection is one of the most important issues requiring utmost attention from companies' management because of its effects on organizations' strategic and operational success. The paper presents a novel study with the usage of fuzzy multi-criteria decision making approach with interval Type-2 fuzzy sets as well as with the representation of a real life case study to make the most effective decision on the location selection problem.

The recent studies have addressed that there is lack of industrial applications of Type- 2 fuzzy sets. So the study, apart from the literature, employs interval Type-2 fuzzy sets for facility location selection problem to cope with high and more uncertainty in the decision making processes. To the best knowledge of the authors, there is no study using IT2FSs for location selection problems. However, the literature demands more studies conducted in the other industrial fields using Type-2 fuzzy sets ${ }^{9}$.

The application of fuzzy TOPSIS based on Type-2 fuzzy sets to the problem supports the view that uncertainty and vagueness is evaluated better by using Type-2 fuzzy sets rather than using Type- 1 fuzzy sets. ${ }^{44-}$ ${ }^{64}$ As indicated by the authors, the fuzzy method helps to measure uncertainty related with words which may be subjective for different people during the evaluation and selection processes.

In this study, a single-facility location problem is considered. Future studies are suggested to analyze multi-facility location problems by expanding the model with the mathematical models. In future studies, the fuzzy TOPSIS method may also be integrated with the other multi-criteria decision making approaches such as fuzzy AHP, fuzzy Electre I-II, and fuzzy Promethee I-II, and another linguistic scale that allows stating unsymmetrical corresponding relationship ${ }^{89-90}$ can be adopted. Then, the results can be compared with the proposed approach. Lastly, the researchers are suggested to integrate fuzzy multi-criteria decision making methods with Type-2 fuzzy sets and Geographical Information System (GIS). As a digital database management system, GIS can include large volumes of spatially distributed data from a variety of sources and stores, analyzes and displays the accumulated information depending on the specifications determined by users. ${ }^{91}$ 


\section{Acknowledgements}

We would like to thank to the company for sharing confidential data, for their valuable contribution to the study and for their enthusiasm.

\section{References}

1. J. Heizer and B. Render, Operations Management, 6th edn. (Prentice Hall, NJ, 2001).

2. B. Kobu, Üretim Yönetimi (Production Management), 11th edn. (Avc1ol Basım Yayın, Istanbul, 2003).

3. R. Russell and B. W. Taylor, Operations Management, 4th edn. (Prentice Hall, 2003).

4. N. Slack, S. Chambers and R. Johnston, Operations Management, 4th edn. (Prentice Hall, 2004).

5. R. Haigh, Selecting a US plant location: The management decision process in foreign companies, Columbia J. World Bus. 25(3) (1990) 22-31.

6. J. Yang and H. Lee, An analytic hierarchy process decision model for facility location selection, Facilities. 15(9/10) (1997) 241-254.

7. P. Kumar and R. K. Singh, A fuzzy AHP and TOPSIS methodology to evaluate 3PL in a supply chain, J. Model. Manage. 7(3) (2012) 287-303.

8. J. M. Mendel, Advances in Type-2 fuzzy sets and systems, Inform. Sciences. 177 (2007) 84-110.

9. T. Dereli, A. Baykasoglu, K. Altun, A. Durmusoglu, and I. B. Türksen, Industrial applications of Type-2 fuzzy sets and systems: A concise review, Comput. Ind. 62 (2011) 125-137.

10. S.- M. Chen and L. W. Lee, Fuzzy multiple attributes group decision-making based on the interval Type-2 TOPSIS method, Expert Syst. Appl. 37 (2010) 27902798.

11. J. Current, H. Min and D. Schilling, Multiobjective analysis of facility location decisions, Eur. J. Oper. Res. 49(3) (1990) 295-307.

12. P. K. Dey and E. K. Ramcharan, Analytic hierarchy process helps select site for limestone quarry expansion in Barbados, J Environ. Manage. 88 (2008) 1384-1395.

13. M. Tabari, A. Kaboli, M. B. Aryanezhad, K. Shahanaghi, and A. Siadat, A new method for location selection: A hybrid analysis, Appl. Math. Comput. 206 (2008) 598606.

14. I. Dogan, Analysis of facility location model using Bayesian Networks, Expert Syst. Appl. 39 (2012) 10921104.

15. R. J. Kuo and S. S. Kao, A decision support system for locating convenience store through fuzzy AHP, Comput Ind. Eng. 37 (1999) 323-326.

16. R. J. Kuo, S. C. Chi and S. S. Kao, A decision support system for selecting convenience store location through integration of fuzzy AHP and artificial neural network, Comput. Ind. 47 (2002) 199-214.
17. J. Korpela and M. Tuominen, A decision aid in warehouse site selection, Int. J. Oper. Prod. Econ. 45(1) (1996) 169-180.

18. P. Thomas, Y. Chan, L. Lehmkuhl and W. Nixon, Obnoxious-facility location and data-envelopment analysis: A combined distance-based formulation, Eur. $J$. Oper. Res. 141 (2002) 495-514.

19. F. Y. Partovi, An analytic model for locating facilities strategically, Omega. 34 (2006) 41-55.

20. G. Tuzkaya, S. Onut, U. R. Tuzkaya and B. Gulsun, An analytic network process approach for locating undesirable facilities: An example from Istanbul, Turkey, J. Environ. Manage. 88 (2008) 970-983.

21. O. Saatcioglu, Mathematical programming models for airport site selection, Transport. Res. B-Meth. 16(6) (1982) 435-447.

22. R. L. Francis, L. F. McGinnis and J. A. White, Locational analysis, Eur. J. Oper. Res. 12(3) (1983) 220-252.

23. H. W. Hamacher and S. Nickel, Classification of location models, Location Sci. 6(1-4) (1998) 229-242.

24. J. Current, S. Ratick and C. ReVelle, Dynamic facility location when the total number of facilities is uncertain: A decision analysis approach, Eur. J. Oper. Res. 110(3) (1998) 597-609.

25. M. Badri, Combining the analytic hierarchy process and goal programming for global facility location-allocation problem, Int. J. Oper. Prod. Econ. 62(3) (1999) 237-248.

26. C. Canel, B. M. Khumawala, J. Law and A. Loh, An algorithm for the capacitated, multi-commodity multiperiod facility location problem, Comput. Oper. Res. 28 (2001) 411-427.

27. S. Melkote and M. S. Daskin, Capacitated facility location/network design problems, Eur. J. Oper. Res. 129 (2001) 481-495.

28. V. Verter, An integrated model for facility location and technology acquisition, Comput. Oper. Res. 29 (2002) 583-592.

29. E. W. L. Cheng and H. Li, Exploring quantitative methods for project location selection, Build Environ. 39(12) (2004) 1467-1476.

30. P. N. Thanh, N. Bostel and O. Péton, A dynamic model for facility location in the design of complex supply chains, Int. J. Prod. Econ. 113(2) (2008) 678-693.

31. A. Klose and A. Drexl, Facility location models for distribution system design, Eur. J. Oper. Res. 162(1) (2005) 4-29.

32. A. B. Arabani and R. Z. Farahani, Facility location dynamics: An overview of classifications and applications, Comput. Ind. Eng. 62 (2012) 408-420.

33. L. A. Zadeh, Fuzzy Sets, Inform. Control. 8 (1965) 338353.

34. C. Kahraman, D. Ruan and I. Dogan, Fuzzy group decision-making for facility location selection. Inform. sciences. 157 (2003) 135-153.

35. S. Y. Chou, Y. H. Chang and C. Y. Shen, A fuzzy simple additive weighting system under group decision-making 
for facility location selection with objective/subjective attributes, Eur. J. Oper. Res. 189 (2008) 132-145.

36. C. Y. Shen and K. T. Yu, A generalized fuzzy approach for strategic problems: The empirical study on facility location selection of authors' management consultation client as an example, Expert Syst. Appl. 36(3) (2009) 4709-4716.

37. K. Anagnostopoulos, H. Doukas and J. Psarras, A linguistic multicriteria analysis system combining fuzzy sets theory, ideal and anti-ideal points for location site selection, Expert Syst. Appl. 35(4) (2008) 2041-2048.

38. P. Dheena and G. Mohanraj, Multi-criteria decisionmaking combining fuzzy set theory, ideal and anti-ideal points for location site selection, Expert Syst. Appl. 38 (2011) 13260-13265.

39. A. Awasthia, S. S. Chauhanb and S. K. Goyal, A multicriteria decision making approach for location planning for urban distribution centers under uncertainty, Math. Comput. Model. 53 (2011) 98-109.

40. S. - C. Ngan, Decision making with extended fuzzy linguistic computing, with applications to new product development and survey analysis, Expert Syst. Appl. 38 (2011) 14052-14059.

41. M. N. Mokhtarian, A new fuzzy weighted average (FWA) method based on left and right scores: An application for determining a suitable location for a gas oil station, Comput. Math. Appl. 61(10) (2011) 31363145.

42. N. N. Karnik and J. M. Mendel, Centroid of a Type-2 fuzzy set. Inform. Sciences. 132 (2001) 195-220.

43. I. B. Turksen, Type 2 representation and reasoning for CWW, Fuzzy Set. Syst. 127 (2002) 17-36.

44. Z. Zhang and S. Zhang, A novel approach to multi attribute group decision making based on trapezoidal interval Type-2 fuzzy soft sets, Appl. Math. Model. 37 (2013) 4948-4971.

45. R Sepulveda, O. Castillo, P. Melin, A. Rodriguez-Diaz and O. Montiel, Experimental study of intelligent controllers under uncertainty using Type-1 and Type-2 fuzzy logic, Inform. Sciences. 177 (2007) 2023-2048.

46. N. N. Karnik, J. M. Mendel and Q. Liang, Type-2 fuzzy logic systems, IEEE T. Fuzzy Syst. 7(6) (1999) 643-658.

47. A. Kazemzadeh, S. Lee and S. S. Narayanan, An interval Type-2 fuzzy logic system to translate between emotionrelated vocabularies, in Proc. Interspeech (Brisbane, Australia, 2008), pp. 2747-2750.

48. A. Celikyilmaz and I. B. Turksen, Modeling uncertainty with fuzzy logic with recent theory and applications, in Studies in Fuzziness and Soft Computing, 240 (Springer, Germany, 2009).

49. R. John, Type 2 Fuzzy Sets: An Appraisal of Theory and Applications. Int. J. Unc. Fuzz. Knowl. Based Syst., 06, 563 (1998) 563-576.

50. J. M. Mendel, Fuzzy Type-2 Sets and System: , IEEE Computational Intelligence Magazine. 2(1) (2007) 20-29
51. S. Miller and R. John, An Interval Type-2 Fuzzy multiple echelon supply chain model, Knowl-Based. Syst. 23 (2010) 363-368

52. C. Kahraman, İ. Sari and E. Turanoğlu, Fuzzy analytic hierarchy process with Type-2 fuzzy sets, in Proc. 10th Int. FLINS Conf. on Uncertainty Modeling in Knowledge Engineering and Decision Making, eds. C. Kahraman, E. Kerre and F.T. Bozbura (Istanbul, Turkey, 2012) pp. 201212.

53. T. - Y. Chen, A linear assignment method for multiple-criteria decision analysis with interval Type-2 fuzzy sets, Appl. Soft. Comput. 13 (2013) 2735-2748.

54. E. Celik, O. N. Bilisik, M. Erdogan, A. T. Gumus and H. Baracli, An integrated novel interval Type-2 fuzzy MCDM method to improve customer satisfaction in public transportation for Istanbul, Transport. Res. E-Log. 58 (2013) 28-51.

55. T. Dereli and K. Altun, Technology evaluation through the use of interval Type-2 fuzzy sets and systems, Comput. Ind. Eng. 65 (2013) 624-633.

56. S.- C. Ngan, A Type-2 linguistic set theory and its application to multi-criteria decision making, Comput. Ind. Eng. 64 (2013) 721-730.

57. N. Zamri and L. Abdullah, A new linguistic variable in interval type-2 fuzzy entropy weight of a decision making method, in $17^{\text {th }}$ Asia Pasific symposium on Intelligent and Evolutionary systems, IES2013, Procedia Comput Science. 24 (2013) 42-53.

58. S.-M. Chen and C.-Y. Wang, Fuzzy decision making systems based on interval type-2 fuzzy sets, Inform. Sciences. 242 (2013) 1-21.

59. Y. Jiang and Y. Tang, An interval type-2 fuzzy modelof computing with words, Inform. Sciences. 281 (2014) 418442.

60. C. Kahraman, B. Öztayşi, İ. Uçal Sarı and E. Turanoğlu, Fuzzy analytic hierarchy process with interval type-2 fuzzy sets, Knowl-Based. Syst. 59 (2014) 48-57.

61. L. Abdullah and L. Najib, A new type-2 fuzzy set of linguistic variables for the fuzzy analytic hierarchy process, Expert Syst. Appl. 41 (2014) 3297-3305.

62. Y. Maali and N. Mahdavi-Amiri, A triangular type-2 multi-objective linear programming model and a solution strategy, Inform. Sciences. 279 (2014) 816-826.

63. D. Wu and J. M. Mendel, A comparative study of ranking methods, similarity measures and uncertainty measures for interval Type-2 fuzzy sets, Inform. Sciences. 179 (2009) 1169-1192.

64. S.- M. Chen and L.- W. Lee, Fuzzy multiple attributes group decision-making based on the ranking values and the arithmetic operations of interval Type-2 fuzzy sets, Expert Syst. Appl. 37 (2010) 824-833.

65. W. Wang, X. Liu and Y. Qin, Multi-attribute group decision making models under interval Type-2 fuzzy environment, Knowl-Based. Syst. 30 (2012) 121-128.

66. Z. Eren and C. E. Bozdağ, An extended method for fuzzy multiple attribute group decision making based on interval Type-2 fuzzy sets, in Proc. 10th Int. FLINS Conf. 
on Uncertainty Modeling in Knowledge Engineering and Decision Making, eds. C. Kahraman, E. Kerre and F.T. Bozbura (Istanbul, Turkey, 2012) pp. 164-170.

67. S.- M. Chen and C. Y. Wang, Fuzzy decision making systems based on interval Type-2 fuzzy sets, Inform. Sciences. 242 (2013) 1-21.

68. T.-Y. Chen, An ELECTRE-based outranking method for multiple criteria group decision making using interval type-2 fuzzy sets, Inform. Sciences. 263 (2014) 1-21.

69. L. Zadeh, The concept of a linguistic variable and its application to approximate reasoning, Part 1, Inform. Sciences. 8 (1975) 199-249.

70. H. Siahkali and M. Vakilian, Interval Type-2 fuzzy modeling of wind power generation in Genco's generation scheduling, Electr. Pow. Syst. Res. 81(8) (2011) 1696-1708

71. World Cement; Higher, Faster, Stronger in Efficiency, Palladian Publications Ltd., England 43(6) (2011).

72. K. Erşen and E. Büyükyazıc1, Economic news from the sector: Turkish cement sector, in Cement and Concrete World, 17 (2012) pp. 36-43.

73. İ. Otay and F. Çebi, An integrated multi-criteria decision making methodology for facility location selection problem under fuzzy environment: application in cement sector, in Proc. 10th Int. FLINS Conf. on Uncertainty Modeling in Knowledge Engineering and Decision Making, eds. C. Kahraman, E. Kerre and F.T. Bozbura (Istanbul, Turkey, 2012) pp. 279-284.

74. R. Z. Farahani, M. SteadieSeifi and N. Asgari, Multiple criteria facility location problems: A survey, Appl. Math. Model. 34(7) (2010) 1689-1709.

75. L. J. Krajewski and L. P. Ritzman, Operations management: Strategy and analysis (Prentice Hall, 2002).

76. İ. Ertuğrul and N. Karakaşoğlu, Comparison of fuzzy AHP and fuzzy TOPSIS methods for facility location selection, Int. J. Adv. Manuf. Tech. 39(7-8) (2008) 783795.

77. J. Sarkis and R. P. Sundarraj, Hub location at Digital Equipment Corporation: A comprehensive analysis of qualitative and quantitative factors, Eur. J. Oper. Res. 137(2) (2002) 336-347.

78. M. Ekmekçioğlu, T. Kaya and C. Kahraman Fuzzy multicriteria disposal method and site selection for municipal solid waste, Waste Manage. 30(8-9) (2010) 1729-1736.

79. S. - M. Chen, M. - W. Yang, L. - W. Lee and S. - Z. Yang, Fuzzy multiple attributes group decision making based on ranking interval Type-2 fuzzy sets, Expert Syst. Appl. 39 (2012) 5295-5308.

80. H. Aras, Ş. Erdoğmuş and E. Koç, Multi-criteria selection for a wind observation station location using analytic hierarchy process. Renew. Energy. 29(8) (2004) 13831392.

81. Z. Adeli and A. Khorshiddous, Application of geomorphology in urban planning: Case study in landfill site selection, Procedia - Social and Behavioral Sciences, 19 (2011) 662-667.

82. H. K. Gupta, Encyclopedia of Solid Earth Geophysics, (Springer, The Netherland, 1989).

83. E. Conrad, S. Misenar and J. Feldman, Cissp Study Guide (Syngress, USA, 2012).

84. P. A. Alsop, H. Chen and H. Tseng, The Cement Plant Operations Handbook for Dry-Process Plants, 5th edn. (Tradeship Publications Ltd., UK, 2007).

85. S. Topbas, Regulating clinker quality, World Cement, 43(4) (2012) 91-97.

86. M. Christiansena, K. Fagerholta, T. Flatbergc, Ø Haugena, O. Klosterc and E. H. Lunda, Maritime inventory routing with multiple products: A case study from the cement industry, Eur. J. Oper. Res. 208(1) (2011) 86-94.

87. J. J. Buckley, Fuzzy hierarchical analysis, Fuzzy Set Syst, 17 (1985) $233-247$.

88. J. Zeng, M. An and N. J. Smith, Application of a fuzzy based decision making methodology to construction project risk assessment, Intern J. Proj Manage, 25 (2007) 589-600.

89. G. Zhang, J. Ma, J. Lu, Emergency management evaluation by a fuzzy multi-criteria group decision support system, Stoch Env Res Risk A, 23(4) (2009) 517527.

90. J. Lu, Y. Zhu, X. Zeng, L. Koehl, J. Ma, G. Zhang, A linguistic multi-criteria group decision support system for fabric hand evaluation, Fuzzy Optim Decis Making, 8(4) (2009) 395-413.

91. D. Fatta, P. Saravanos and M. Loizidou, Industrial waste facility site selection using geographical information system techniques, Intern. J. Environmental Studies, 56 (1998) 1-14 